\title{
Preparando vitela e produzindo mulheres - cadernos de receita como locais de escrita sobre construções do feminino
}

Preparando carne de ternera y produciendo mujeres - recetarios de cocina como lugares de escritura sobre las construcciones de lo femenino

Preparing women and producing calf - cookbooks as sites of writing about gender constructions

\author{
Juzelia de Moraes \\ juzeliamoraes@gmail.com \\ Universidade Federal de Goiás - Programa de Pós-Graduação em Arte e Cultura Visual
}

\section{RESUMO}

O presente artigo busca analisar a partir de cadernos e blogs de receitas culinárias, questões a respeito da construção discursiva sobre o gênero feminino ao longo da história e seus diálogos com a contemporaneidade. Para tanto traço esta escrita a partir dos enfoques da pesquisa narrativa (MARTINS E TOURINHO, 2009; BOLIVAR, DOMINGO e FERNANDEZ, 2001) e da concepção dos blogs e cadernos de receitas como possíveis arquivos (SALOMON, 2001 e FOUCAULT, 1997). Ressalto ainda a importância do acesso à escrita nos processos de construções do feminino (Cunha, 2006), bem como as questões identitárias que emergem das práticas culinárias (CERTEAU e GIARD, 2000, 2003; MONTANARI, 2009).

Palavras-chave: feminino, caderno de receitas, blogs de culinária e arquivos

\section{RESUMEN}

Este artículo tiene el propósito de analizar, a partir de los recetarios de cocina y los blogs de culinaria, cuestiones sobre la construcción discursiva del género femenino a lo largo de la historia y sus diálogos con la contemporaneidad. Por lo tanto, abordo este tema desde la perspectiva de la investigación narrativa (TOURINHO y MARTINS, 2009; BOLÍVAR, DOMINGO y FERNANDEZ, 2001), problematizando los blogs de culinaria y los recetarios de cocina como posibles archivos de análisis (SALOMON, 2001 y FOUCAULT, 1997). Enfatizo la importancia del acceso a la escrita en los procesos de construcción de lo femenino (CUNHA, 2006) así como los problemas sobre identidad que surgen de las prácticas culinarias (CERTEAU y GIARD, 2000, 2003, MONTANARI, 2009).

Palabras-clave: femenino, recetario de cocina, blogs de culinaria, archivos 


\section{ABSTRACT}

This article seeks to examine, from cookbooks and recipes blogs, questions about the discursive construction of the feminine gender throughout history and its dialogues with the contemporaneity. In order to do that, I do this written text from the approaches of narrative research (MARTINS and TOURINHO, 2009; BOLIVAR, DOMINGO and FERNANDEZ, 2001) and the concept of blogs and cookbooks as archives (SALOMON, 2001 and FOUCAULT, 1997). I emphasize the importance of access to writing in the process of construction of the feminine (CUNHA, 2006) as well as identity issues that emerge from practices (CERTEAU and GIARD, 2000, 2003; MONTANARI, 2009).

Keywords: feminine; blogs and notebooks of recipes; archives 


\section{ARQUIVOS CULINÁRIOS-IDENTITÁRIOS}

Oriunda da pesquisa narrativa, a atenção sobre a experiência do sujeito desde seus fazeres mais ordinários como um mote de análise acerca de registros de práticas culturais solidifica-se cada vez mais no âmbito acadêmico. É fato a resistência a investigações de cunho qualitativo, estas ainda centradas em procedimentos de análise que se abrem à subjetividade dos indivíduos estudados, ainda são vistas sob olhares preconceituosos por significativa parcela acadêmica, isto sobretudo em razão da impossibilidade de prover certezas e respostas precisas, como muitos acreditam ser possível através de pesquisas quantitativas. Entretanto, o interesse em partir de aspectos do sujeito, em tempos anteriores ignorados, não apenas amplia as possibilidades investigativas, mas também reconfigura noções acerca da pertinência do que se é estudado na atualidade.

Dentre os objetos analisados dentro de uma perspectiva narrativa, amiúde podem ser encontrados diários pessoais, cadernos que por meio de relatos cotidianos, fatos que a priori poderiam ser compreendidos como banais, acabam por reconstruir por meio da escrita e dos elementos outros que venham a constituí-lo, os contextos socioculturais em que foram produzidos (BOLIVAR; DOMINGO E FERNANDEZ. 2001). Por trás de páginas amareladas, recortes de imagens que revivem tempos remotos, habitam histórias não apenas individuais, mas estas inseridas em tempos históricos específicos, marcados por condutas, políticas e poderes definidos e habitados por indivíduos.

Apesar da consciência da existência de diários produzidos por homens, a noção de diários pessoais configura-se muito mais aliada à figura feminina, nisto construindo não apenas as características do objeto com fins relacionados diretamente ao emocional, sentimental (e aí talvez resida um reforço no preconceito para com a análise de tal objeto), mas sobretudo a perspectiva de relatos de tempos específicos, sob a ótica feminina. E neste sentido, creio, amplia-se a possibilidade de uma interessante perspectiva dos engendramentos sociopolíticos, uma vez que às mulheres foi destinado (ou permitido) um modo de participação social muito distinto ao dos homens. Às mulheres foi negligenciada por muito tempo a possibilidade de uma participação efetiva em assuntos de ordem política, por exemplo. Todavia, essa noção de participação efetiva também se constrói sob uma ótica masculina. Ou seja, pode-se pensar por meio de uma perspectiva não falocêntrica como as mulheres foram atuantes na construção da sociedade atual?

Ao fazer a relação entre a carne de vitela e a produção do gênero feminino penso nos espaços e circunstâncias condicionados aos dois no intuito comum de construção de um ser a partir da ação de sistemas cultuais e suas normas. Percebo aspectos comuns à construção do gênero feminino enquanto constituído a partir de limites bem definidos e conjuntos de regras formuladas sob os interesses de uma hegemonia masculina, de mesmo modo que a produção de carne de vitela em que os bezerros são retirados logo cedo do contato com suas mães e submetidos a inúmeros procedimentos $^{1}$ que lhes impõem condições de existência limitadas por interesses de um grupo dominante. Admito certo tom feminista na comparação realizada, contudo é claro (e frequentemente discutido) o fato de que as mulheres buscam cada vez mais a conquista de seus espaços, o que não se discute a respeito dos homens, por exemplo. Nisto, foram buscadas brechas ao longo dos anos em que o feminino foi encontrando suas formas de pronunciar-se, mesmo que inicialmente de modo pouco expandido ao âmbito social.

A esse respeito Maria Teresa Santos Cunha (2006) traça algumas considerações sobre como os diários femininos podem reconstruir cenários de determinada geração, sob a ótica da mulher. Ao realizar a investigação de dois conjuntos de diários produzidos por duas catarinenses entre 1964 e 1974 , verifica a partir dos relatos de fatos aparentemente corriqueiros, o tenso momento político marcado pela ditadura militar. A forte presença de elementos que faziam referência à luta contra a ditadura (músicas, passeatas, notícias de jornal) aparecem frequentemente em meio a questões de ordem amorosa e religiosa, por exemplo.

\footnotetext{
1 Um exemplo é o fato de que os bezerros são isolados em pequenos compartimentos individuais onde não podem realizar grandes movimentos, o que faz com que desenvolvam pouco a musculatura tornando sua carne mais macia para o consumo alimentício.
} 
Por meio desse material, a autora discorre sobre a possibilidade e a relevância de investigação de escritos pessoais, de narrativas biográficas, para estudos acerca de questões que permeiam construções de determinada sociedade, de determinada época. Nestes relatos carregados da espontaneidade dos sentimentos que perpassavam as autoras dos diários, tem-se uma observação sobre o momento político do período, contudo em uma ampla perspectiva que atingia as inúmeras facetas da vida social dos indivíduos. Talvez por meio desses relatos que não tinham por objetivo traçar um panorama político-histórico, seja possível o conhecimento acerca de questões pertinentes e que não se encontram nos livros de história, para o estudo de fatos marcantes da sociedade. E nisto, cabe a perspectiva feminina como agente social, ignorada por longos anos.

Partindo desta concepção de diários femininos como locais de relatos de experiências cotidianas, como local que guarda - seja por meio da escrita ou por meio de imagens - memórias, segredos, reflexões... alio ao diário feminino como possível objeto de investigação narrativa, outro artefato tradicionalmente associado ao gênero feminino: o caderno de receitas culinárias. Este objeto frequentemente transcende sua função utilitária e acaba assumindo características de diário, contudo, em minha concepção particular, sendo menos rigoroso quanto à freqüência na escrita, nos registros e no modo de produção (neste, várias pessoas podem contribuir com receitas sugeridas).

Entretanto os cadernos de receitas guardam amiúde em seu interior mais do que meros modo de preparo de comidas. Contam tradições, condutas sociais, desejos por vezes não verbalmente confessos. Contam, bem como os diários femininos, momentos histórico-sociais.

Neste sentido, cadernos de receita culinária e diários femininos podem ser compreendidos como arquivos que registram os fatos de determinada cultura e período. E, sobretudo, aliados à perspectiva de investigação narrativa podem servir como importantes ferramentas de estudo sobre determinada sociedade atentando para aspectos cotidianos que a configuraram compreendendo de modo mais amplo questões que anteriormente foram ignoradas em análises científicas.
Deste modo, proponho no presente artigo discorrer sobre cadernos de receitas compreendidos como arquivos históricos, refletindo sobre seus modos de construção, sobre como seus elementos podem relatar aspectos do cenário social em que são produzidos e ainda como podem contar questões sobre o feminino, produzidas e refletidas nas páginas que também guardam receitas. Para tanto, inicio as considerações pensando na relevância da escrita nestes processos de construção de locais que abrigam relatos pessoais, bem como na escrita quando pensada em relação ao gênero feminino.

\section{ANOTANDO RECEITAS, RELATANDO MODOS DE SER}

Quando Michel de Certeau (2000) discorre acerca prática escriturística sob a perspectiva dos fazeres cotidianos, traça apontamentos sobre tal fazer associado a intuitos progressistas de concepção e construção da sociedade moderna. Ainda, sugere reflexões sobre a escrita como um fazer legitimador da alta cultura, em sentido oposto a história construída e difundida a partir da oralidade. Mas, a meu ver, uma das questões mais interessantes despertadas pelas considerações de Certeau diz respeito à prática da escrita como um modo de relação reflexiva do sujeito com o mundo em que está inserido.

Quando o autor se propõe a definir o ato de escrever, cita como um dos elementos principais neste processo, a página em branco. Sobre isso, menciona Certeau:

(...) um espaço 'próprio' circunscreve um lugar de produção para o sujeito. Trata-se de um lugar desenfeitiçado das ambigüidades do mundo. Estabelece o afastamento e a distância de um sujeito em relação a uma área de atividades. Oferece-se a uma operação parcial mas controlável. Efetua-se um corte no cosmo tradicional, onde o sujeito era possuído pelas vozes do mundo. Coloca-se uma superfície autônoma sob o olhar do sujeito que assim dá a si mesmo o campo de um fazer próprio. Gesto cartesiano de um corte instaurador, como um lugar de escritura, do domínio (e isolamento) de um sujeito diante do objeto. (2000, p. 225) 
Esse processo não apenas cria um sistema de ordenação da reflexão acerca de determinado objeto e a relação do sujeito para com esse, mas ainda lança a possibilidade da invenção de mundos. E assim, a invenção de sujeitos inscritos nestes. A página em branco surge como a possibilidade de apreensão de algo, e nisto reside também a noção desse domínio oriundo, como mencionado anteriormente, do conhecimento da escrita.

Ao criar esse espaço de relação com o mundo, ao tecer comentários, produzir notas reflexivas sobre determinado tema, o sujeito situa-se e relaciona-se com este trazendo para o diálogo aspectos oriundos de suas subjetividades. Cria locais de questionamento em que se pensa só, mas não se desloca de seu ser social, traçando assim diálogos (talvez inconscientes) com os inúmeros elementos constituintes do universo que habita, bem como com os inúmeros indivíduos que o constituem.

Neste sentido, retomo o objeto foco mencionado no início - o diário - e penso-o como um local a priori aparentemente constituído por uma única voz, mas onde na verdade transitam inúmeras pessoas e elementos que acabam por determinar o processo de autoria. Assim, o diário não reflete apenas as questões trazidas por uma única pessoa, mas evoca também a fala de inúmeras outras, suas histórias em conexão às do narrador.

Assim, o diário atua como local que acolhe as experiências de determinado sujeito, local de organização da observação acerca do vivido e de como foi vivido. A respeito da organização da experiência individual e de como esta não se dá de modo isolado ao contexto, lembro apontamentos de Martins e Tourinho (2009), que reforçam a concepção de que a experiência individual está inserida invariavelmente em um contexto social, de modo que "construímos nossas experiências individuais de modo relacional, ou seja, sempre em contexto, sempre no mundo social”. (p. 6-7)

Nossas falas e pensamentos individuais são sempre permeados por aquilo que nos afeta e, por conseguinte nos constitui. Assim, é importante lembrar que a escrita que busca pensar as experiências individuais ocorre dentro de determinado contexto farto de elementos passíveis de diálogos com o sujeito.
Pensando tais questões em relação à produção de diários femininos, é de significativa relevância observar o contexto, espaço destinado (e porque não "permitido") às mulheres ao longo dos anos. Surgem, a passos lentos, considerações e estudos que propõem a observação de uma história observada a partir do ponto de vista feminino ou que, no mínimo, busca pensar as distinções produzidas para os sexos dentro de um contexto social e há muito consolidadas mediante a fala produzida pela história. A esse respeito Whitney Chadwick (2007) traz alguns apontamentos voltados à construção de uma concepção acerca do gênero feminino consolidada pelo intermédio da linguagem e por muito reforçada pelos discursos da história da arte. Ainda, Chadwick faz referência aos estudos pós-estruturalistas apontando outras perspectivas de observação acerca da construção do gênero que compreendem estes como determinados por forças econômicas, culturais e políticas.

Destarte tais notas auxiliam a pensar como ao longo dos anos foi construído um discurso e local para o feminino, muito mais do que pelo feminino. E nisto reside o ponto importante de observação acerca da escrita feminina, que só teve início como uma prática possível às mulheres em fins do século XIX, o qual diz respeito a como tal conhecimento permitiu que pudessem, a partir da escrita, começar a pensar-se e sobretudo dentro de um âmbito sociocultural específico.

A partir do estudo de arquivos oriundos de escritos femininos é possível a observação de uma história construída diante de outra perspectiva não relatada nos livros. Faz-se possível a relativização, bem como maior compreensão de determinados fatos e momentos históricos. Solidifica-se na atualidade um interesse em observar, estudar a história daqueles que historicamente tiveram suas vozes ignoradas, nisto buscando mapear as trilhas dos sistemas de poder que atuam sobre a sociedade que habitamos. Segundo Salomon

Há uma luta e uma vontade de saber dos arquivos, quer dizer, torná-los acessíveis, disponibilizá-los à mesa de leitura e transformá-los em objeto de interrogação histórica, deslocá-los das sombras que o poder lhes reservou, dá-los à luz do dia do conhecimento. (...) Com 
os arquivos, saber dos ausentes é possível. (2001, p. 8)

Assim, os diários femininos podem ser pensados não como meros locais constituídos por relatos irrelevantes do dia a dia, mas como brechas de um colocar-se no mundo diante do modo como o mundo permitia. Por trás de simples relatos de fazeres cotidianos, olhares sobre a vida comum, habitam histórias que remontam sistemas de organização política e distinções entre os papéis possíveis para os distintos sexos no âmbito social. Uma história erigida sob o ponto de vista feminino, sem o propósito de construir considerações históricas, mas que ganha por meio da perspectiva contemporânea a relevância de material rico de elementos que traçam momentos passados.

Maria Teresa Cunha (2006) faz referência a inúmeras questões perceptíveis por meio da análise de diários femininos, que permitem construir um panorama da vida feminina em meados do século XIX. Em suas notas fica clara também a distinção que se percebe em relação à vida feminina em classes sociais distintas, isto observado por meio da produção escrita de um caderno íntimo, o que já enfatiza a relação do conhecimento associada às classes sociais mais abastadas, bem como relaciona a produção destes diários em razão das casas possuírem cômodos individuais em que as moças poderiam meditar na privacidade de um local só seu. O que evidentemente não era possível para meninas pertencentes a famílias mais pobres e que mal possuíam um local digno como moradia. A produção destes diários também estava conectada ao ócio da mulher burguesa e de seu preparo para vida matrimonial.

Por receberem pouca ou mesmo nenhuma formação profissional, não podiam aspirar a um trabalho e ficavam mais resignadas a espera do casamento. Além disso, o diário servia para prolongar o aprendizado da escritura. Através dele, as escreventes interiorizavam normas sociais e aprendiam um certo domínio sobre si mesma, mas parece consensual o fato de que havia poucas mulheres que continuassem o diário depois do casamento. (CUNHA, 2006, p. 121)
Nos estudos de Cunha ainda há um ponto que merece atenção acerca da produção de diários femininos, o qual diz respeito ao fato de que estes eram fruto de uma concepção econômico burguesa. Neste período as mulheres de famílias burguesas eram as responsáveis pela administração dos arquivos do lar, gerenciando, por exemplo os livres de raison e as correspondências familiares. Isto sugere o quanto os pensamentos desenvolvidos acerca da vida íntima, das questões cotidianas que mereciam atenção, descritas por meio do relato, estavam intrinsecamente ligados à condição de administradora do lar e à família.

Ou seja, a aprendizagem da escrita estendida às mulheres, apesar de configurar uma conquista, não foi a parte de uma estrutura social masculina lançada para o feminino. A escrita feminina ancorava-se em um projeto educativo voltado às necessidades da sociedade moderna, contudo, não ampliando o local de submissão bem delimitado e destinado às mulheres. Considerando-se que estes diários íntimos foram durante muito tempo incentivados por padres e professores como um meio de reflexão (e controle) sobre si, constituiu-se em um mecanismo de auto-vigia implantado por um modelo de conduta da sociedade patriarcal moderna.

Tais objetos íntimos surgem então como arquivos da trajetória de conquistas femininas e ainda das forjadas conquistas atribuídas às mulheres. E nisto não negligencio a importância do acesso feminino ao letramento, apenas diante justamente de uma perspectiva histórica que se propõe ao estudo dos fatos não como um roteiro a ser observado, mas sim a ser pensado por meio de pontos de vista múltiplos, relativizo de que modo a escrita foi efetivamente relevante para fazer soar a voz das mulheres para além do espaço permitido a elas.

Contudo, o crescente interesse em arquivos que relatam histórias de pessoas comuns e nisto, a atenção a escritos femininos, aponta para a compreensão da relevância de dados oriundos das cotidianidades, bem como daqueles sujeitos que por muito pareceram irrelevantes do ponto de vista histórico, como constituintes de uma história bem mais complexa do que se teve conhecimento até a atualidade. Ainda, a riqueza contida nos detalhados relatos presentes nestes diários, bem como a densidade proporcionada pelo 
narrar para si mesmo a intimidade, sem a preocupação com o mundo exterior, deixa por vezes a sensação de uma veracidade maior de informações oriundas desses arquivos pessoais. Entretanto, buscando não cair no tentador juízo de valor, penso os diários no mínimo como significativos objetos que evocam por meio de relatos cotidianos pessoais, identidades construídas em meio aos inúmeros âmbitos de sistemas sociais específicos.

Na contemporaneidade a escrita reconfigura-se sendo significativamente afetada pelos inúmeros mecanismos de comunicação a que se tem acesso com facilidade. Nestes estão presentes também novas configurações acerca do gênero feminino, que a priori sugere as inúmeras transformações no que diz respeito a este e a seu espaço, mas em que também são possíveis observações acerca de como determinadas questões referentes à submissão permanecem sólidas, mesmo quando, por vezes, veladas. Neste sentido, ao se propor atentar para as transformações pelas quais passou a mulher ao longo destes anos, buscando em diários íntimos a reflexão sobre questões que definiam suas condutas e espaços, é importante também atentar para a forma como os arquivos atuais (blogs, facebook, twitter...) também relatam a partir das práticas cotidianas a história atual.

O processo antes solitário e que buscava o relato da intimidade para si mesma, agora ganha outro status ao entrar em um sistema de redes sociais. Ainda estão presentes intimidades (não intenciono aqui entrar no mérito da questão da veracidade do que é relatado), mas agora estas não parecem buscar a reflexão sobre si mesma, parecem buscar o diálogo (com seus pares) sobre si. Assim, o sentido da escrita parece ganhar outro sentido, não mais de reflexão individual, mas de relato para o círculo de amizades (e neste caso é importante relativizar o sentido que é dado ao termo amizade, uma vez que atualmente inúmeras pessoas que mal conhecemos são sugeridas pelas redes sociais como "amigos") sobre não apenas questões do dia a dia, mas também relatos enfáticos (mas que pensam-se sutis) sobre eventos relevantes da vida.

Neste sentido é importante pensar que também o modo de escrita pessoal se reconfigura em razão de recursos visuais. E aqui encaminho a consideração para o foco de atenção deste artigo, uma vez que intenciono pensar nos cadernos de receitas culinárias como locais de reflexão sobre o feminino e que, a meu ver comumente foram produzidos por meio de escrita, mas amiúde abertos a inserção de imagens e elementos outros que relatam não apenas hábitos alimentares dos sujeitos que os produziram, mas permitem a observação de questões que transitam por detrás do fazer culinário. Para tanto buscarei pensar nas questões referentes construções do feminino por meio da perspectiva dos cadernos de receita, compreendendo-os como arquivos que relatam motes para além da culinária. Ainda, viso traçar um paralelo entre os cadernos de receita culinária e os blogs que possuem como foco principal a gastronomia de modo a discorrer sobre os distintos modos construção destes e a possibilidade de investigação de questões do feminino neles presentes.

\section{DO FOGÃO À LENHA AO MICRO-ONDAS}

Exatamente como a linguagem, a cozinha contém e expressa a cultura de quem a pratica, é depositária das tradições e das identidades de grupo. Constitui assim um extraordinário veículo de autorepresentação e de comunicação: não é apenas um instrumento de identidade cultural, mas talvez seja o primeiro modo para entrar em contato com culturas diversas. (Montanari, 2009, p. 11)

Partindo da citação de Massimo Montanari, amplio sua colocação a respeito da possibilidade de, por meio da cozinha, entrar em contato com culturas diversas e sugiro que por meio dela (de seus aparatos, particularidades, sujeitos que a constituem...) pode-se também traçar um panorama histórico-social a partir das cotidianidades que dela emergem, pode-se também conhecer mais amplamente determinada cultura e os atores que dela participam e participaram.

A alimentação, o fazer culinário, engendram questões que vão muito além ao mero preparo de um alimento. As ritualizações presentes nestes (convite para a ceia, preparativos para a realização do prato, modos de servir, gestualidade do alimentar-se...) denotam particularidades de grupos específicos e sugerem olhares acerca dos indivíduos dentro destes grupos e seus processos de aquisição e reprodução de sa- 
beres e condutas. Ou seja, a partir da cotidianidade em que habitam os fazeres culinários, vislumbram-se pela repetição de gestos, perpetuação e ressignificação de costumes, sistemas de tradição bem como seus desdobramentos (GIARD, 2003)

Destes elementos, rituais e condutas, pode-se verificar em cadernos de receitas culinárias o espaço que registra tais assuntos e ainda, a abertura ao diálogo entre a culinária e suas relações com demais questões da vida social. Neste sentido é relevante mencionar que dentre os variados modos de produção de cadernos de receita, um dos que mais me desperta a atenção, sendo objeto de meu estudo, é a estruturação do caderno como um local em que as receitas dividem seu espaço com elementos e informações que não necessariamente se referem à comida. Assumem de certo modo a função de um diário aberto a relatos pessoais que se configuram para além da narrativa escrita. E, sobretudo, relatos pessoais que possivelmente não se percebem como tal, mas que por meio das escolhas dos temas que adentram o caderno, acabam sugerindo traços da identidade de um indivíduo.

Para o desenvolvimento de tais reflexões, parti inicialmente da observação do caderno de receitas de minha mãe, sobretudo por sempre ter me encantado a forma como criava um local repleto de informações das mais distintas ordens. Neste, recortes de revistas e jornal, poesias, artigos sobre beleza e dicas para o cuidado do lar, habitam o mesmo local que as receitas que frequentemente adquiria, mas que dificilmente concretizavam-se (seja pela falta de público aberto a experimentá-las, seja pelo valor despendido para a realização dos pratos). Impulsionada por este objeto, senti desde cedo o desejo de realização de meu caderno de receitas, construído de mesmo modo que o dela. Contudo, fui percebendo em sua construção o evidente fato de que as questões que adentravam em meu caderno eram sobre temas diferentes aos escolhidos por minha mãe. Nisto, fui observando variações de construção de um mesmo gênero em momentos temporais distintos e evidenciados por meio de registros contidos em um caderno de receitas, em um fazer cotidiano.

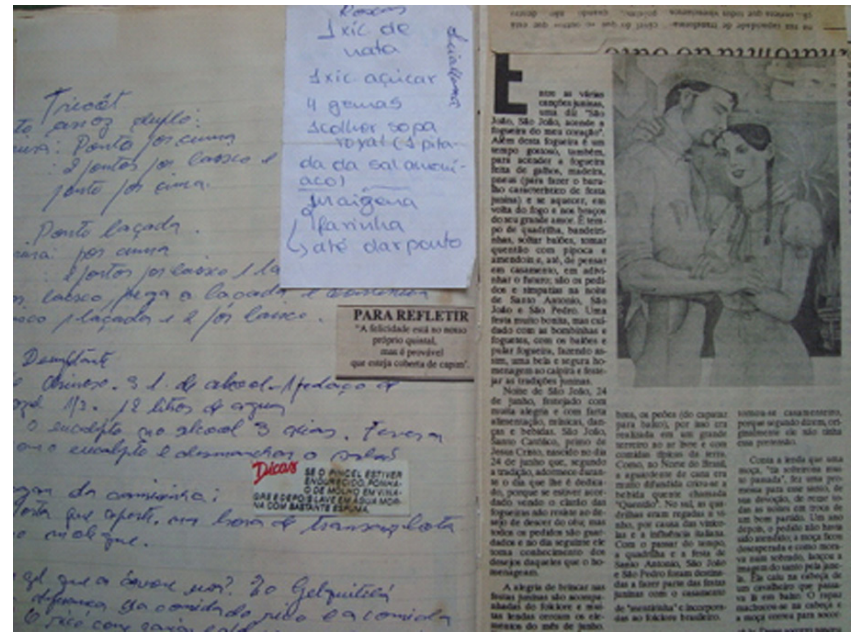

Imagem 1 - Imagem de páginas do caderno de receitas de minha mãe.

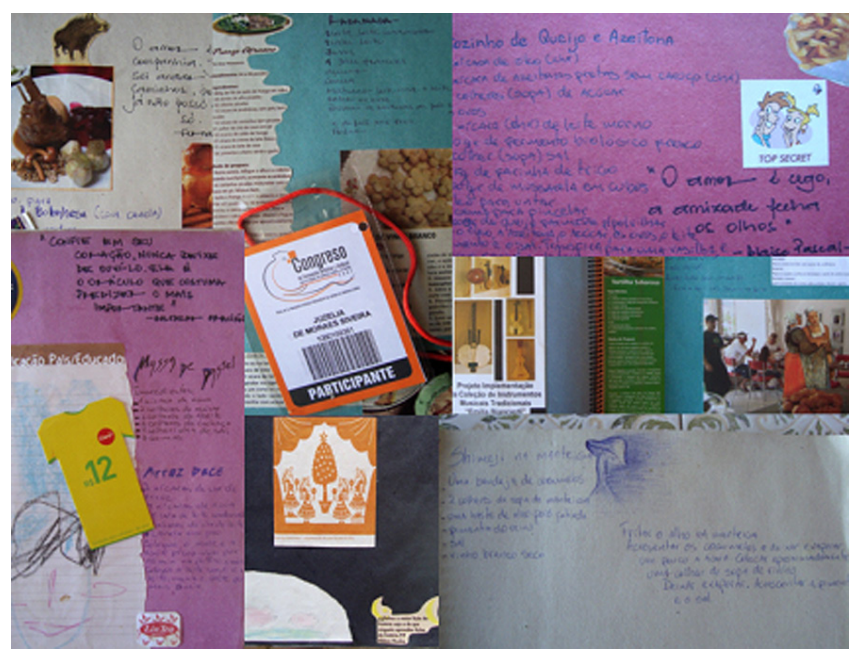

Imagem 2 - Imagens de páginas de meu caderno de receitas.

As imagens dos dois cadernos trazem elementos que dialogam, se aproximam e distanciam ritmados pela marca do período de criação de cada um deles. Se por um lado um dos cadernos é marcado por elementos que remetem a fazeres que sugerem a atuação em uma vida pública, atividades exercidas em espaços de ensino e lazer, o outro traz relatos imagéticos voltados a conhecimentos e ações desenvolvidas no dia a dia do lar. A atenção a esses recortes, imagens extraídas do cotidiano vão ao encontro do que aponta a cultura visual ao compreender que as imagens que percorrem o dia a dia dos sujeitos geram significados atuando sobre a produção de suas identidades (TAVIN, 2009).

Percebo assim, variações de construções e de referências de gênero que se desdobram com o passar dos anos e mediante os afetos de tempos distintos, estes passíveis de análise 
por meio de uma produção caracterizada justamente pela perpetuação de tradições. Assim, mantêm-se os objetos, contudo, reconfiguram-se suas formas e elementos de construção.

Quando Marlon Salomon discorre sobre a imersão nos arquivos para além da crença na certeza proporcionada pela metodologia da ciência historiadora, menciona que esta imersão "não é o encontro com os papeis inertes da história, mas do pensamento como uma potência ativa. Que põe a inteligência em alerta. Que mobiliza o pensamento" (SALOMON, 34). Deste modo, penso estes cadernos como arquivos que não apenas registram sistemas de tradições perpassadas amiúde de mãe para filha, mas sobretudo como objetos determinados por estruturas reguladoras de condutas para o gênero feminino. Ou seja, estes registros que outrora poderiam ser verificáveis apenas como pertencentes exclusivamente ao âmbito da culinária, podem ser observados diante de uma perspectiva voltada aos estudos de gênero como ricas fontes de investigação acerca da construção de discursos e condutas em torno deste tema.

Nestes objetos, referências sobre concepções, discursos, posturas em torno da questão do feminino. Entretanto estes discursos que permeiam estes cadernos não se configuram aprisionados em seu tempo de origem, são passíveis de desdobramentos de significados outros ao estabelecerem conversações com as transformações dos tempos.

O arquivo não é (...) o que recolhe a poeira dos enunciados que novamente se tornaram inertes e permite o milagre eventual de sua ressurreição; é o que define o modo de atualidade do enunciado-coisa; é o sistema de seu funcionamento. Longe de ser o que unifica tudo o que foi dito no grande murmúrio confuso de um discurso, longe de ser apenas o que nos assegura a existência no meio do discurso mantido, é o que diferencia os discursos em sua existência múltipla (...). (FOUCAULT, 1997, 147)

Assim, ao se construir um olhar investigativo sobre como os cadernos de receitas culinárias, que aqui compreendo como possíveis arquivos, pode-se remontar discursos de épocas anteriores e também evocar questões que perpetuam-se e se desdobram em outras tantas. Partindo desta concepção, ao recorrer aos cadernos de receitas pensando-os em sua capacidade arquivística, ainda enquanto dispositivo de reflexão sobre questões que tangem o feminino, compreendo a possibilidade de estabelecer diálogos entre modos de engendrar e pensar um mesmo objeto em tempos distintos e as reconfigurações dos enunciados ao passar dos anos.

Neste sentido, busco pensar como, a partir das páginas gastas e demarcadas pelos efeitos de seu uso cotidiano, constituintes dos cadernos de receitas de mãe e avós, surgem produções caracterizadas por modos variados de construção e que carregam em si referências de seu tempo. E nisto remeto-me inclusive a possibilidade da existência não material do caderno de receitas, verificável por exemplo em blogs da internet.

Ao me propor analisar cadernos de receitas atuais, verifiquei que um dos aspectos mais relevantes nesse sentido dizia respeito ao fato de que estes são contemporaneamente construídos no espaço virtual, o que determina significativamente suas características em razão dos modos de interação do sujeito com este ambiente. Anteriormente mencionei, ao traçar analogias entre diários e cadernos de receitas, que uma das características da realização de diários era a deste ser uma produção íntima, frequentemente individual, de caráter auto-reflexivo. Percebo ainda na realização de cadernos de receita virtuais, moldes de diários íntimos e auto-reflexivos, todavia a questão da individualidade não parece se constituir mais como algo desejável. Pelo contrário, é de certo modo esperado que sejam comentados os temas que se originam destes dois aspectos (intimidade e auto-reflexividade), que hajam interações de amigos, família, colegas.

Tal ponderação volta-se novamente para a questão da escrita feminina e do acesso, agora possível, não só ao domínio da escrita, mas também a possibilidade de se pronunciar por meio desta em âmbito público. O que talvez soe como algo irrelevante, se pensado em relação ao restrito espaço permitido às mulheres durante muitos anos, sugere não apenas uma conquista, mas também uma maior compreensão acerca do desejo de fazer-se cotidianamente ouvir, observar. (Evidentemente não ignoro o fato de que homens 
também produzem blogs e inclusive voltados a receitas culinárias, todavia centro aqui meu interesse na observação sobre o feminino.). Estes espaços de criação de si, estes modos de agir, de modo algum me parecem desconectados de sentimentos que possuem raízes anteriores e que dizem respeito aos distintos papéis por longos anos atribuídos e destinados a homens e mulheres.

Ao se realizar uma pesquisa na internet sobre blogs de culinária (blogs de receitas, na verdade), frequentemente tem-se acesso não apenas a receitas, mas a inúmeros outros temas que de algum modo sugerem traços de construções de feminilidades em que alguns pontos parecem comuns, inclusive a identidades femininas de períodos anteriores Vale ressaltar que com isso não pretendo sugerir que as mulheres deveriam romper com todas as características de uma feminilidade construída em tempos anteriores, marcados significativamente por algumas restrições às mulheres O que pretendo é problematizar é de que modo (ou até que ponto) a perpetuação de algumas questões frequentemente associadas à submissão feminina, podem conservar-se ou ressignificar-se diante das transformações ocorridas ao longo dos anos. Entretanto, por fazer parte deste gênero ao qual lanço o olhar, inevitavelmente acabo trazendo por vezes discursos pessoais carregados por concepções construídas sob a afirmação de meu gênero em sua busca por espaços igualitários. Estabelecidas as fragilidades, bem como os intuitos da reflexão, retomo a concepção acerca dos blogs de culinária.

Imagens de bolos, fotos de viagens, dicas de beleza e ponto cruz transitam e dialogam em espaços anunciados como destinados a sugestões de receitas. De mesmo modo, em muitos cadernos de receita produzidos de modo tradicional podia-se ter acesso também a estes temas mencionados, todavia por meio de recortes de revista, escritos, ou fotografias. Ainda, é possível perceber variações no tratamento e configuração destes materiais: as fotos de viagens, por exemplo, frequentemente trazem imagens do namorado ou marido e dificilmente de uma grande família como costumava ocorrer em fotografias mais antigas.

Além das inúmeras questões que podem ser observadas por meio de temas variados que adentram estes espaços desti- nados a ensinar, sugerir e compartilhar receitas, a própria observação sobre as transformações que marcam os pratos e ingredientes selecionados acabam por sugerir modos distintos de vidas femininas contemporâneas em relação à de suas mães e avós, por exemplo. A freqüente sugestão de receitas rápidas e fáceis sugere um estilo de vida em que os afazeres do lar raramente são as únicas atividades realizadas no dia a dia. Disto, pode-se ponderar não apenas a respeito da conquista em relação ao mercado de trabalho, mas também sobre os estudos no ensino superior e ainda sobre a responsabilidade de prover o alimento para a família que, apesar da crescente atuação masculina no âmbito da culinária, ainda parece atribuída significativamente às mulheres.

Os cadernos de receita, se pensados em relação ao propósito a que se destinavam em tempos passados, contam uma história do feminino voltado ao cuidado da família, ao compromisso da mulher com relação à alimentação de marido e filhos. Sabe-se que juntamente com o enxoval era providenciado um caderno de receitas que a mãe passaria para a filha como um modo de ratificar qual deveria ser sua conduta enquanto esposa. Além disso, esses cadernos serviam também como um importante meio de estabelecimento de legados de uma família, de perpetuação de suas tradições.

Assim, é interessante pensar que os elementos que constituem cadernos de receita de gerações mais antigas acabam por relatar questões que falam de uma vida feminina mais doméstica, em que raramente as mulheres que produziam tais objetos possuíam um trabalho outro que não o do lar. Neste sentido é interessante pensar também na estrutura econômica de cada período, e nisto me reporto a Gayle Rubin (1993) quando pensa, sob a perspectiva do marxismo em observação ao sistema capitalista, que o trabalho doméstico contribui para o sistema de produção no sentido de dar subsídios ao trabalhador (Comida, roupa limpa, cama feita. Isto tudo, sem remuneração). Menciona que tal conjectura, apesar de explicar a relevância das mulheres para o sistema capitalista, não pode ser a chave para pensar a origem da opressão feminina. Apesar de concordar com a afirmação da autora, creio ser o sistema capitalista não a gênese da opressão, mas um fator determinante em inúme- 
ros aspectos no que diz respeito aos papéis assumidos pelos distintos sexos na estrutura socioeconômica.

$\mathrm{Na}$ atualidade ao exercer uma dupla jornada de trabalho (emprego e lar), a "mulher" multiplica-se de modo a transcender um sujeito ao longo dos anos (e ainda muito) definido em escassas denominações como "mãe" e "esposa", por exemplo. É importante pensar que estas designações frequentemente são estabelecidas em discursos cotidianos que constroem categorias para homens e mulheres em que se criam leis, verdades, pronunciadas na informalidade da vida social, mas que possuem significativo poder na regulação de um sistema sexista (MARTíN ROJO; GÓMEZ ESTEBAN, 2004). De mesmo modo, os discursos vão se reconfigurando em razão desta multiplicidade de facetas que a mulher vai assumindo e podem ser perceptíveis nas inúmeras personas que habitam um mesmo sujeito e que se pronunciam comumente por meio dos variados temas tanto de interesse, como de atuação presentes nos referidos blogs. Que fazeres e características contam a constituição do gênero feminino diante da perspectiva contemporânea?

Importante dizer que com essa questão não ignoro que muIheres de gerações anteriores também eram constituídas por inúmeras identidades, por afetos oriundos de âmbitos distintos, contudo o que penso é sobre como ampliam-se espaços, deslocam-se fronteiras discursivas no que tange aos gêneros. Buscarei me fazer mais clara a partir de apontamentos de Judith Butler:

Se alguém "é" uma mulher, isso certamente não é tudo o que esse alguém é; o termo não logra ser exaustivo (...) porque o gênero nem sempre se constitui de maneira coerente ou consistente nos diferentes contextos históricos e porque o gênero estabelece intersecções com modalidades raciais, classistas, étnicas, sexuais e regionais de identidades discursivamente constituídas. Resulta que se tornou impossivel separar a noção de "gênero" das intersecções políticas e culturais em que invariavelmente ela é produzida e mantida. (BUTLER, 2003, p. 20)
Neste sentido, o que os cadernos de receitas contemporâneos construídos a partir do ambiente virtual trazem, são o reflexo do tempo, do contexto em que são realizados. Os modos possíveis de dizer da identidade feminina em meio a múltiplas facetas que pode constituir uma mulher contemporânea, inclusive, podendo esta cultivar características que remetem a "donas do lar".

Deste modo, pensar nestes cadernos produzidos virtualmente como possíveis arquivos, e utilizados como dispositivos de diálogo com cadernos de receitas tradicionais, pode ser não apenas um modo de levantar uma problematização acerca de questões que focam na construção do feminino ao longo dos anos, mas ainda pensar na própria noção de arquivo $^{2}$. Ao partir de um recurso que não encontra-se no passado, distancia-se a compreensão de que arquivos remetem necessariamente à memória, a tempos longínquos. Assim, pensando a partir das considerações de Foucault que compreende os arquivos como permeados pela ordem discursiva, em que residem "sistemas que instauram os enunciados como acontecimentos (tendo suas condições e seu domínio de aparecimento) e coisas (compreendendo sua possibilidade e seu campo de utilização)" (FOUCAULT, 1997, p. 146), penso a possibilidade deste local contemporâneo (blogs de receitas) que se propõe a muito mais do que guardar receitas, como um objeto que pode abrigar narrativas pessoais, experiências vivenciais, isto tudo mediado e construído por sistemas discursivos.

Ao buscar estabelecer diálogos entre os cadernos de receita tradicionais e os blogs de receitas contemporâneos tive por intuito centrar a atenção acerca de como tais locais pertencentes ao âmbito do cotidiano, produzidos por mulheres comuns, poderiam traçar por meio de seus elementos constituintes, possíveis noções de construções do feminino ao longo dos anos. E nisto, a observação sobre como os sistemas discursivos que constroem este gênero também são construídos por seus próprios sujeitos, seja pela afirmação negação e perpetuação de modos de dizer-se.

\footnotetext{
2 Contudo, ressalto que ao dizer isso não estou colocando como necessária a utilização de um recurso contemporâneo como possível arquivo apenas quando este encontra-se em diálogo com um objeto do passado.
} 


\section{COMBINADOS OS SABORES..}

No presente artigo me propus a traçar aproximações iniciais acerca de como cadernos de receita culinária, foco de minha pesquisa doutoral, podem impulsionar análises acerca das relações de gênero, isto compreendendo-os como arquivos que guardam elementos pessoais, relatam identidades e suas construções. Para tanto, centrei o foco desta escrita na observação sobre o feminino, levantando questões referentes à construção deste gênero ao longo dos anos até a atualidade, isto partindo de pontos suscitados pelos cadernos e blogs de receitas no que tange a práticas, bem como suas especificidades, realizadas por mulheres.

Buscando pensar os cadernos de receitas e os blogs de culinária como possíveis arquivos que podem promover a reflexão sobre as construções do feminino, esta verificada por meio dos elementos que constituem este objeto, por sistemas que transitam no entorno de suas produções, me propus a pensar tal objeto sob o olhar da história não como uma fonte das verdades que construíram o passado. Ao pensar tais relações não apenas a observação sobre perspectivas distintas sobre o mesmo tema se fez possível, mas ainda como a atenção acerca de como arquivos contemporâneos podem possibilitar a análise sobre os processos discursivos em latente construção.

A investigação de um objeto tradicionalmente construído por mulheres, isto sob os enfoques da pesquisa narrativa, traz a observação sobre vozes que no passado estiveram fora dos interesses acadêmicos e ainda a compreensão sobre a relevância de tecer outros olhares sobre temas que foram construídos ao longo da história apenas sob perspectiva masculina. Neste sentido, o que podem suscitar os cadernos de receita e os blogs de culinária é a atenção sobre como foram determinados os espaços destinados às mulheres, bem como ainda o são. E nisto, cabe atentar para o fato de como também as mulheres são responsáveis por estes lugares e muitas vezes por seus sistemas de sujeição.

Os processos de acesso a inúmeros âmbitos e fazeres que durante muito tempo foram exclusivos de homens - e nisto a questão da aprendizagem da leitura e escrita - contam histórias de realizações, bem como do árduo caminho traçado para que estas se fizessem possíveis. É possível verificar inclusive que mesmo algumas questões observadas como conquistas ainda desenvolvem-se por meio de condições desiguais, em que se passa a ter acesso a um espaço tradicionalmente masculino, mas ainda tendo a responsabilidade em relação a um outro, feminino. Deste modo, a tão proferida igualdade entre os sexos, a qual se acredita estarmos atingindo efetivamente, deveria na verdade ser observada não apenas nos termos dos espaços conquistados, mas também dos ainda impostos às mulheres.

Na manutenção de regimes sexistas, a compreensão da relevância que a linguagem possui nos processos que tanto pretendem moldar sujeitos, gêneros e também fazê-los frequentemente sob um dissimulado discurso que sugere igualdade. Na produção e perpetuação de objetos, de fazeres cotidianos, a possibilidade de reiteração de normas e padrões, bem como a possibilidade de subverter seu uso tradicional. Assim, a produção de um local que se origina do intuito de trocar e compartilhar receitas culinárias, mas que também abre-se a incorporação de elementos e falas que contam a mulher que os produz constitui-se como um profícuo material de investigação acerca do feminino e dos processo de construção deste no âmbito social.

Evidentemente esta escrita se constitui uma breve investigação sobre como este objeto oriundo do cotidiano e as práticas do seu entorno podem evocar questões acerca dos distintos papéis atribuídos a homens e mulheres na sociedade. Entretanto, a partir desta sucinta proposta reflexiva foi possível vislumbrar os inúmeros e possíveis temas que podem emergir deste estudo, ainda mais quando ampliado ao masculino, tanto como em razão do desenvolvimento a partir de minhas próprias experiências.

\section{REFERÊNCIAS}

BOLIVAR, A. ; DOMINGO, J. ; FERNANDEZ, M.. (2001) La investigación biográfico-narrativa em educación: enfoque y metodologia. Madrid: La Muralla.

BUTLER, Judith. (2003) Problemas de Gênero. Feminismo e Subversão da identidade. Rio de Janeiro: Civilização Brasileira.

CERTEAU, Michel. (1994) A Invenção do cotidiano: 1. Artes de fazer. Petrópolis: Ed. Vozes.

GIARD, Luce; MAYOL, Pierre. (1996) A invenção do co-

tidiano: 2, morar,cozinhar. Petrópolis: Artes de Fazer. 
CHADWICK, Whitney. (2007) Preface. In: Chadwick, Whitney. Women, art, and society. London: Thames \& Hudson.

CUNHA, Maria Teresa Santos. (2006) Escrever sobre si diários íntimos e construção de subjetividades. In.: SOMMER, Luís Henrique; BUJES, Maira Isabel Edelweiss. Educação e cultura contemporânea - articulações, provocações e transgressões em novas paisagens. Canoas: Editora da ULBRA.

FOUCAULT, Michel. (1997) Arquivologia do Saber. Rio de Janeiro: Forense Universitária.

MARTINS, Raimundo; TOURINHO, Irene. (2009) Pesquisa narrativa: concepções, práticas e indagações. In: Anais do /l Congresso de Educação, Arte e Cultura-CEAC. Santa Maria.

MONTANARI, Massimo (org.). (2009) O Mundo na Cozinha - História, Identidade, Trocas. São Paulo: Editora Senac.

MARTÍN ROJO, Luisa; GÓMEZ ESTEBAN, Concepción. (2004) Lenguaje, identidades de género y educación. In.: LOMAS, Carlos. Los Chicos también Lloran, Barcelona: Paidós Ibérica.

RUBIN, Gayle. (1993) O tráfico de mulheres: notas sobre a economia política do sexo. Recife: S.O.S Corpo.

SALOMON, Marlon (org.). (2001) Saber dos arquivos. Goiânia: Edições Ricochete.

TAVIN, Kevin. (2009) Contextualizando visualidades no cotidiano: problemas e possibilidades do ensino da cultura visual. In: MARTINS, Raimundo; TOURINHO, Irene (Orgs.). Educação da cultura visual: narrativas de ensino e pesquisa. Santa Maria: Editora da UFSM. 